\title{
Biodiversity of North Atlantic and North Sea calanoid copepods
}

\author{
Grégory Beaugrand $^{1,2, *}$, Philip C. Reid ${ }^{1}$, Frédéric Ibañez ${ }^{2}$, Benjamin Planque ${ }^{3}$ \\ ${ }^{1}$ Sir Alister Hardy Foundation for Ocean Science, The Laboratory Citadel Hill, Plymouth PL1 2PB, United Kingdom \\ ${ }^{2}$ Observatoire océanologique, Laboratoire d'océanologie biologique et écologie du plancton marin, BP 28, 06230 Villefranche-sur-Mer, France \\ ${ }^{3}$ The Centre for Environment, Fisheries and Aquaculture Science, Pakefield Road, Lowestoft NR33 OHT, United Kingdom
}

\begin{abstract}
Spatial patterns in pelagic biodiversity are the result of factors acting from a global to a local scale. The global patterns have been studied intensively using taxa such as foraminifera and euphausiids. However, these studies do not allow direct comparisons of neritic and oceanic regions or examination of relationships between local and regional patterns of pelagic diversity. Here we present a map of the diversity of calanoid copepods, a key planktonic group, summarising $40 \mathrm{yr}$ of continuous monthly investigations in the North Atlantic and North Sea. The high number of samples (168162) allowed mesoscale patterns in diversity to be detected for the first time at an ocean-basin level. Our results demonstrate pronounced local spatial variability in planktonic diversity and refine previous global studies at a lower resolution. They form a baseline at which long-term changes in planktonic diversity can be better assessed and ecosystem management plans implemented.
\end{abstract}

KEY WORDS: Pelagic diversity $\cdot$ Calanoid copepods $\cdot$ North Atlantic $\cdot$ North Sea $\cdot$ Continuous Plankton Recorder (CPR) survey

Resale or republication not permitted without written consent of the publisher

In the pelagic marine realm, current spatial patterns in diversity are the result of evolutionary, biogeographic and more local abiotic, biotic and ecological factors (Angel 1998). At the evolutionary scale, variability in biodiversity is related to geological events such as plate tectonics and orbital forcing (Angel 1993, Molfino 1994). These events have led to the opening or closure of seas, modification of global circulation patterns and oscillation of sea levels, which together have shaped pelagic biodiversity (Angel 1998). These large-scale events should still be considered in the explanation of present day patterns of biogeography and species ecology (Williamson 1998).

Until now, the science of biodiversity has mainly focussed on these global features, and especially lati-

*E-mail: gbea@wpo.nerc.ac.uk tudinal gradients, in increasing diversity from the poles to the tropics (Stehli et al. 1969, Angel 1991). Different maps of diversity have been displayed (Ruddiman 1969, Reid et al. 1976, Pierrot-Bults 1998) and hypotheses proposed (Rohde 1992, Rutherford et al. 1999). Although these maps have played a significant role in identifying factors responsible for observed patterns at a global scale, this is not so at a regional level. Indeed, several drawbacks have limited their use. First, the lack of a large data-set has prevented the detection of accurate boundaries between oceanic provinces. Second, neritic regions were often neglected, hindering comparison of diversity patterns in oceanic and neritic areas. Third, the mapping methods or the distribution of samples on which maps were based were often not clearly indicated, decreasing their relevance. However, information on diversity at a regional scale is essential for understanding year-to-year fluctuations of planktonic communities as well as for ecosystem management.

There is little information on the spatial distribution of copepod biodiversity, despite their importance in marine food webs. High seasonal and ontogenic variations and diel migration would necessitate a high intensity of sampling through seasons in both the day and night. Here we summarise the diversity of calanoid copepods in the North Atlantic and the North Sea based on intensive sampling by the Continuous Plankton Recorder (CPR) for all months and times of day, from 1958 to 1997 . The objectives were (1) to accurately identify the mean location of major systems, (2) to characterise diversity between oceanic and neritic regions as well as their boundaries, and (3) to detect local patterns in diversity in a regional context.

Materials and methods. The CPR survey is an upper layer plankton monitoring programme that has regularly collected about 400 taxa in the North Atlantic and North Sea since 1948 (Warner \& Hays 1994). It is 
operated by a high-speed plankton recorder (about $20 \mathrm{~km} \mathrm{~h}^{-1}$ ) that is towed behind voluntary merchant ships at a depth of approximately $10 \mathrm{~m}$. Despite the near surface sampling, studies have shown that this machine gives a satisfactory picture of the epipelagic zone (Lindley \& Williams 1980, Williams \& Lindley 1980, Batten et al. 1999). Upon returning to the laboratory, the silk on which plankton is collected, is unwound and cut into sections corresponding to 10 nautical miles and approximately $3 \mathrm{~m}^{3}$ of filtered sea water (Hays 1994). Calanoid copepods (108 taxa) were selected because (1) they play a key role in the food web and (2) CPR sampling and identification are optimal with this taxa. Indeed, in most cases $(92.5 \%)$ identification is carried out to species level, except for small calanoids, which are identified to genus, and ParaPseudocalanus, which includes species of both Paracalanus and Pseudocalanus. Data (168162 samples) from January 1958 to December 1997 have been used, as the taxonomic resolution of analysis has been stable over this period.

Fig. 1 summarises the different steps of numerical procedures that led to the average map of diversity. For each of the 168162 samples, taxonomic richness was calculated (Step 1). In this case, taxonomic richness means the mean number of taxa per CPR sample. The

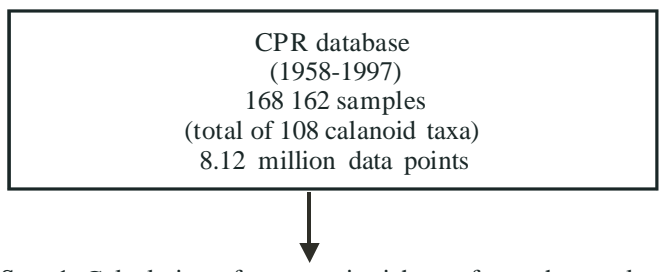

Step 1. Calculation of taxonomic richness for each sample

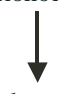

Step 2. Longitude and latitude converted to Lambert coordinates

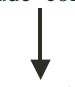

Step 3. Spatial interpolation for each month

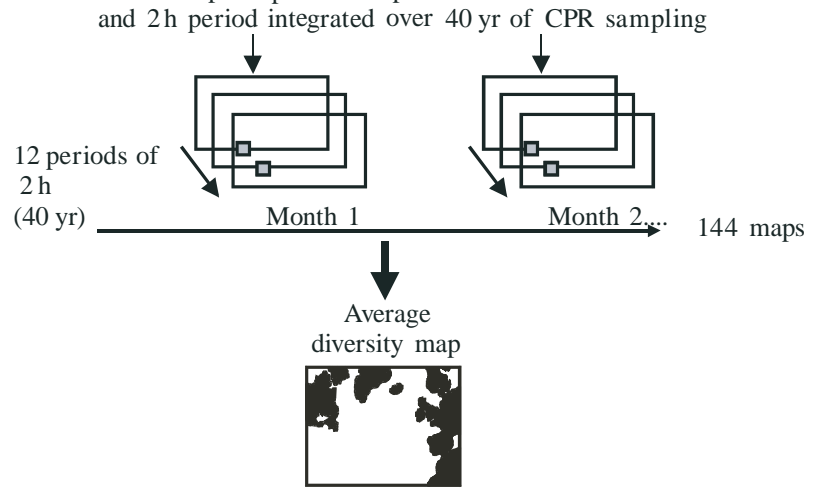

Fig. 1. Successive steps of numerical procedures used to produce the average map of calanoids diversity in the North Atlantic and the North Sea
CPR sampling is irregular in time and space. Samples can be collected at any time of day or night for any month or location. In order to take this heterogeneity into account, spatial interpolations for each month and each $2 \mathrm{~h}$ period were performed. Latitude and longitude were transformed to Lambert coordinates (Step 2). The main advantage of using the Lambert conical projection was to avoid an extreme alteration of distances on the map (Planque et al. 1997). Next, the inverse squared distance method (Lam 1983) was used to produce monthly maps for each $2 \mathrm{~h}$ period (Step 3 ) to take into account seasonal, ontogenic variations and diel vertical migration (a total of 144 maps). In each case, interpolation was realised on a grid of $50 \times 50$ nautical mile (n mile) pixels using a search radius of $250 \mathrm{n}$ mile. Due to a close dependence of diversity indices with size of sample (Magurran 1988), it was important to use the same number of samples for each estimation of diversity. Thus, each estimation was based exactly on 10 samples in a search radius of $250 \mathrm{n}$ mile (maximum distance between the estimator and the sample). If more than 10 neighbours were present in this search area, the 10 nearest ones were selected to estimate the taxonomic richness. If less than 10 neighbours were present in this same search radius, no estimation was calculated. Each pixel was based on exactly 1440 data (10 samples for 144 different times). All spatial interpolations integrated $40 \mathrm{yr}$ of plankton monitoring.

Results and discussion. Fig. 2 displays the mean spatial pattern derived from 144 base maps of the taxonomic richness of calanoids for each month and $2 \mathrm{~h}$ period. As a result of the small CPR sample size, the taxonomic richness should be considered more as an index of diversity than the actual number of taxa. At a regional scale over the North Atlantic, a major contrast is evident between calanoids in subarctic waters (south of Greenland) with low diversity and waters influenced by the Gulf Stream extension ( $\sim 40$ to $50^{\circ} \mathrm{N}$, $\sim 40$ to $50^{\circ} \mathrm{W}$ ), the Bay of Biscay and the southeast North Sea, where taxonomic richness is higher (Fig. 2). There is a clear difference between the eastern oceanic part of the North Atlantic, where a weak contrast in diversity exists, and the western part, where the contrast is sharper, mainly due to the effects of the Gulf Stream extension. A large difference in taxonomic richness also exists between the American and European continental shelves. Above the American shelf, diversity is low probably due to the influence of the Labrador Current that brings only a few species southwards. The opposite situation is found over the European continental shelf, where the effects of the North Atlantic Current, and probably the shelf edge current, transport more species northwards. Over the southwest oceanic part, high diversity may be the result of the Gulf Stream extension that carries subtropical species. 


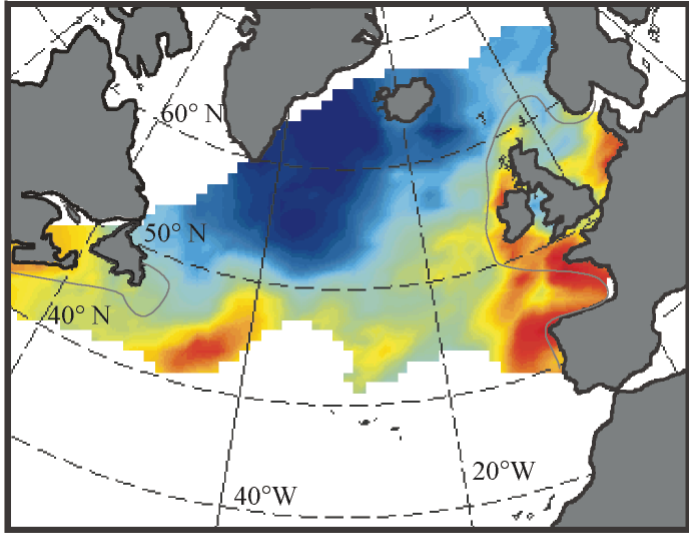

Taxonomic richness per sample

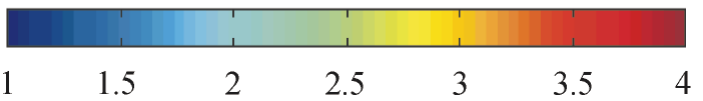

Fig. 2. Mean taxonomic richness of calanoid copepods per CPR sample in the North Atlantic and North Sea. Each pixel is based on exactly 1440 samples to assure that no sampling bias is introduced between regions. Five different diversity indices - the Berger-Parker index (Berger \& Parker 1970), Brillouin diversity (Brillouin 1956), Brillouin evenness (Brillouin 1962), Shannon diversity (Shannon \& Weaver 1962), and Gini coefficient (Lande 1996) - were also calculated and gave similar results to the taxonomic richness used here. Boundaries of continental shelves are indicated by a grey line representing $200 \mathrm{~m}$ depth

This is corroborated by the occurrence in this region of subtropical species such as Candacia ethiopica and Centropages violaceus. At this latitude, the current frequently forms meanders or eddies (Mann \& Lazier 1996) that could mix subtropical, temperate and subpolar species and hence also increase local diversity.

The sharp and irregular contrasts of biodiversity in these regions show that the hypothesis of a progressive increase of diversity from the poles to tropics (Stehli et al. 1969) is altered by a pronounced local variability. In previous studies, this local variability could not be detected because of the weak resolution used. High regional variability observed in the Bay of Biscay and Celtic Sea is a consequence of the conjunction of a number of hydrographic factors. Species that belong to the mid-latitude gyre may reach this zone. The slope current (Pingree \& Le Cann 1992) along the shelf edge break may also contribute to an increase in diversity. Indeed, species indicative of upwelling water such as Calanoides carinatus are detected in this region along the shelf edge break. Finally, interpenetration of both neritic and oceanic species may also increase the number of taxa occurring in this region. Northwards, the effects of seasonal shelf-edge and tidal fronts, and southwards, the influence of the Iberian upwelling, complicate diversity patterns in this region. In the
North Sea, higher diversity is found in the shallow, strongly tidally mixed southeast area due to the presence of coastal species such as Isias clavipes and Labidocera wollastoni.

Fig. 3 shows seasonal and day-night variations in each region. This coefficient is the ratio of the standard deviation to the mean (Scherrer 1984) and gives an indication of the amplitude of seasonal and diel variations. It shows that over the continental shelf and shelf break, seasonality and diel variation are weaker in contrast to oceanic region, where the amplitude is far greater. This difference influences the calculation of mean taxonomic richness (Fig. 2). In particular the contrast between shallow regions of lower diversity and deeper regions of higher diversity is reduced. These characteristics and the effects of seasonal and diel variations make it difficult to directly compare diversity between the southeast North Sea region and the diversity of the Gulf Stream extension, which seem to be similar in Fig. 2.

Knowledge of spatial patterns in plankton diversity in the North Atlantic has been provided mainly by biogeographic or paleoecologic studies using, for example, foraminifera (Ruddiman 1969, Rutherford et al. 1999), euphausiids (Reid et al. 1976), mysids (Angel 1998), or chaetognaths (Pierrot-Bults 1998). At a coarse scale, similar patterns exist between Fig. 2 and the above studies, but differences are also evident at a regional level. Boundaries between the Atlantic Arctic Province of the Atlantic Polar Biome as proposed by Longhurst

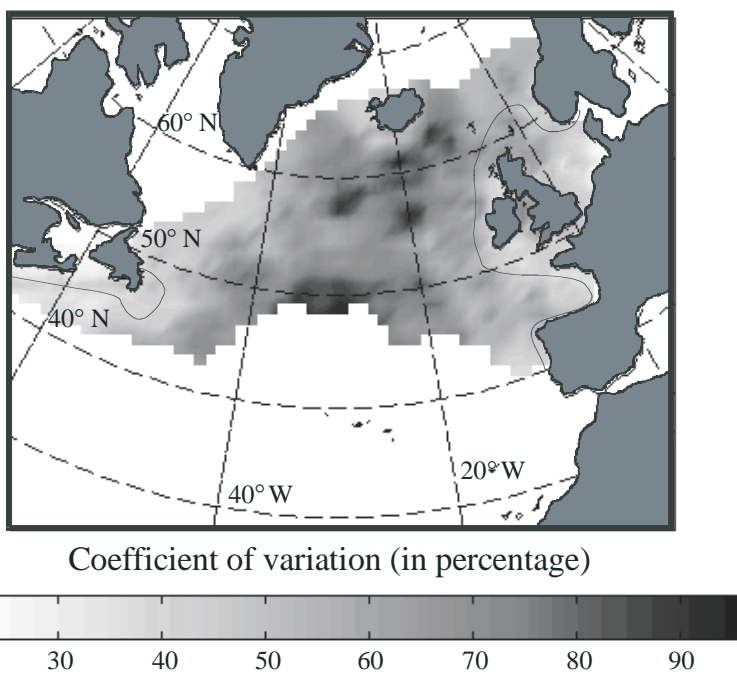

Fig. 3. Coefficient of variation of the mean taxonomic richness of calanoids per CPR sample over the North Atlantic and the North Sea. This coefficient, expressed as percentage, is the ratio of the standard deviation to the mean. This shows greater seasonal and diel variations in oceanic regions in contrast to the shallow ones. Boundaries of continental shelves are indicated by a grey line representing $200 \mathrm{~m}$ depth 
(1998) are refined as well as the northward extension of the Gulf Stream Province belonging to the Atlantic Westerly Winds Biome (Longhurst 1998). Hydrography and behavioural responses by organisms are likely to be responsible for the maintenance of the high diversity structures seen in the Bay of Biscay and the Celtic Sea. In the North Sea, 2 main regions were distinguished: a shallow tidally mixed region in the southeast, and to the north a deeper and stratified area in summer.

Human activities may alter biodiversity in the marine realm through overexploitation, eutrophication, pollution (Omori et al. 1994, Sherman \& Duda 1999) or indirectly by the effects of global warming on large-scale oceanic circulation. Poor knowledge of spatial patterns of biodiversity, however, has limited our assessment of this change. Our diversity map (Fig. 2) summarises $40 \mathrm{yr}$ of investigation to give an average planktonic biodiversity which will enable future changes in climate and anthropogenic forcing to be better assessed. The Gulf Stream extension, identifiable by its diversity, suggests that diversity or indicator species may be used as a proxy variable to study how regional circulation is modified by climatic change. Our results also have practical applications for ecosystem management. In particular, there is an increasing concern about ballast water transfer of aquatic organisms by merchant vessels (Carlton \& Geller 1993, Krause \& Angel 1994, Nehring 1998). The International Maritime Organisation (IMO) has recommended exchange of ballast water in the open ocean to prevent the invasion of exotic species by merchant vessels from one port to another (Hallegraeff 1998). Our map could be used to help identify preferred sites for ballast water exchange. The information provided may also be useful in the implementation of Integrated Coastal Zone Management (ICZM) as defined in Pullen (1998), as well as for the management of Large Marine Ecosystems (LME) as shown in Sherman (1994). This note represents the first product of a project that focuses on spatial and temporal changes in the biodiversity of calanoid copepods in the North Atlantic and the North Sea. More information about the effects of seasonal and interannual variations in diversity are needed, and are being investigated.

Acknowledgements. The authors are grateful to all past and present members and supporters of the Sir Alister Hardy Foundation for Ocean Science, whose continuous efforts have allowed the long-term establishment and maintenance of the CPR data-set. We are particularly grateful to Alistair Lindley, Martin Edwards, Thierry Comtet and 4 anonymous referees for advice and comments on the manuscript. This research was supported by the European Community Research Project No. MAS3-CT98-5058 and the 'Programme National de l'environnement côtier, thème: influence des facteurs hydroclimatiques ou anthropiques sur la variabilité spatio-temporelle des populations et écosystèmes marins' (PNEC art 4).

\section{LITERATURE CITED}

Angel MV (1991) Variations in time and space: is biogeography relevant to studies of long-time scale change? J Mar Biol Assoc UK 71:191-206

Angel MV (1993) Biodiversity of the pelagic ocean. Conserv Biol 7:760-772

Angel MV (1998) Pelagic biodiversity. In: Ormond RFG, Gage JD, Angel MV (eds) Marine biodiversity: patterns and processes. Cambridge University Press, Cambridge, p 35-68

Batten S, Hirst AG, Hunter J, Lampitt RS (1999) Mesozooplankton biomass in the Celtic Sea: a first approach to comparing and combining CPR and LHPR data. J Mar Biol Assoc UK 79:179-181

Berger WH, Parker FL (1970) Diversity of planktonic foraminifera in deep sea sediments. Science 168:1345-1347

Brillouin L (1956) Science and information theory. Academic Press, New York

Carlton JT, Geller JB (1993) Ecological roulette: the global transport of nonindigenous marine organisms. Science 261:78-82

Hallegraeff GM (1998) Transport of toxic dinoflagellates via ships' ballast water: bioeconomic risk assessment and efficacy of possible ballast water management strategies. Mar Ecol Prog Ser 168:297-309

Hays GC (1994) Mesh selection and filtration efficiency of the Continuous Plankton Recorder. J Plankton Res 16: 403-412

Krause DC, Angel MV (1994) Marine biogeography, climate change and society needs. Prog Oceanogr 34:221-235

Lam NSN (1983) Spatial interpolation methods: a review. Am Cartogr 10:129-149

Lande R (1996) Statistics and partitioning of species diversity, and similarity among communities. Oikos 76:5-13

Lindley JA, Williams R (1980) Plankton of the Fladen Ground during FLEX 76 II. Population dynamics and production of Thysanoessa inermis. Mar Biol 57:79-86

Longhurst A (1998) Ecological geography of the sea. Academic Press, London

Magurran A (1988) Ecological diversity and its measurement. Cambridge University Press, Cambridge

Mann KH, Lazier JRN (1996) Dynamics of marine ecosystems: biological-physical interactions in the oceans, 2nd edn. Blackwell Science, Inc, Cambridge, MA

Molfino B (1994) Palaeoecology of marine systems. In: Giller PS, Hildrew AG, Raffaelli DG (eds) Aquatic ecology. Scale, pattern and process. Blackwell Scientific Publications, Cambridge, p 517-546

Nehring S (1998) Non-indigenous phytoplankton species in the North Sea: supposed region of origin and possible transport vector. Arch Fish Mar Res 46:181-194

Omori M, Van Der Spoel S, Norman CP (1994) Impact of human activities on pelagic biogeography. Prog Oceanogr 34:211-219

Pierrot-Bults AC (1998) Biological diversity in oceanic macrozooplankton: more than counting species. In: Ormond RFG, Gage JD, Angel MV (eds) Marine biodiversity: patterns and processes. Cambridge University Press, Cambridge, p 69-93

Pingree RD, Le Cann B (1992) Three anticyclonic Slope Water Oceanic eDDIES (SWODDIES) in the Southern Bay of Biscay in 1990. Deep-Sea Res 39:1147-1175

Planque B, Hays GC, Ibañez F, Gamble JC (1997) Large scale spatial variations in the seasonal abundance of Calanus finmarchicus. Deep-Sea Res I 44:315-326

Pullen JSH (1998) Protecting marine biodiversity and integrated coastal zone management. In: Ormond RFG, Gage JD, An- 
gel MV (eds) Marine biodiversity: patterns and processes. Cambridge University Press, Cambridge, p 394-414

Reid JL, Brinton E, Fleminger A, Venrick EL, McGowan JA (1976) Ocean circulation and marine life. In: Charnock H, Deacon G (eds) Advances in oceanography. Plenum Press, New York, p 65-130

Rohde K (1992) Latitudinal gradients in species diversity: the search for the primary cause. Oikos 65:514-527

Ruddiman WF (1969) Recent planktonic foraminifera: dominance and diversity in North Atlantic surface sediments. Science 164:1164-1167

Rutherford S, D'Hondt S, Prell W (1999) Environmental controls on the geographic distribution of zooplankton diversity. Nature 400:749-753

Scherrer B (1984) Biostatistique. Gaëtan morin éditeur ltée, Montréal

Shannon CE, Weaver W (1962) The mathematical theory of communication. University of Illinois Press, Urbana

Editorial responsibility: Otto Kinne (Editor),

Oldendorf/Luhe, Germany
Sherman K (1994) Sustainability, biomass yields, and health of coastal ecosystems: an ecological perspective. Mar Ecol Prog Ser 112:227-301

Sherman K, Duda AM (1999) An ecosystem approach to global assessment and managment of coastal waters. Mar Ecol Prog Ser 190:271-287

Stehli FG, Douglas RG, Newell RG (1969) Generation and maintenance of gradients in taxonomic diversity. Science 164:947-949

Warner AJ, Hays GC (1994) Sampling by the Continuous Plankton Recorder survey. Prog Oceanogr 34:237-256

Williams R, Lindley JA (1980) Plankton of the Fladen Ground during FLEX 76 I. Spring development of the plankton community. Mar Biol 57:73-78

Williamson M (1998) Marine biodiversity in its global context. In: Ormond RFG, Gage JD, Angel MV (eds) Marine biodiversity: patterns and processes. Cambridge University Press, Cambridge, p 1-17

Submitted: May 5, 2000; Accepted: July 13, 2000

Proofs received from author(s): September 15, 2000 